\title{
Sulfuric Acid Catalyzed Preparation of Alkyl and Alkenyl Camptothecin Ester Derivatives and Antitumor Activity against Human Xenografts Grown in Nude Mice
}

\author{
Zhisong Cao*, Anthony Kozielski, Nick Harris, Dana Vardeman, Beppino Giovanella \\ Christus Stehlin Foundation for Cancer Research, Houston, USA \\ Email: ${ }^{2}$ zcao@stehlin.org
}

Received January 19, 2012; revised February 16, 2012; accepted February 28, 2012

\begin{abstract}
Camptothecin-20-propinate (CZ48) and other camptothecin ester derivatives were prepared by the esterification reactions of camptothecin or 9-nitrocamptothecin with the corresponding acylating agents such as organic acid anhydride or chloride with concentrate sulfuric acid as the catalyst. The sulfuric acid-catalyzed reactions gave high yields of camptothecin ester products.Among the 11 compounds prepared by this method, camptothecin-20-O-propionate, camptothecin-20-O-crotonate, and 9-nitrocamptothecin-20-O-propionate showed good anticancer activity against various types of human tumors grown as xenografts in nude mice. The methodology developed for the preparation of camptothecin esters in this article can be applied to a wide scope of other ester derivatives.
\end{abstract}

Keywords: Anti-Cancer Drugs; Activity; Esterification; Camptothecin; 9-Nitrocamptothecin

\section{Introduction}

Camptothecin, a natural product, was first isolated from a native Chinese tree Camptotheca acuminata by Wall and his coworkers in 1966 [1]. Because of its remarkable anti-tumor activity in animal models, this compound was rushed to the human clinical trials in the late 1960s and early 1970s. Unfortunately, with this compound, the results from these early human clinical studies were disappointing due to intolerable side effects and lack of anti-tumor activity in patients. The molecule of camptothecin contains a six-membered lactone moiety with an $\alpha$-hydroxyl group at the $\mathrm{C} 20$ position. Lactone camptothecin is insoluble in water by itself. The sodium carboxylate, a water-soluble form, of the molecule was thus prepared and used in early human clinical trials. Patients participating in the study did not receive any therapeutic benefits from this open acid form of the drug, and also experienced severe toxicities [2-5]. The subsequent studies showed that carboxylate salt of the molecule has only one-tenth the potency of the lactone form [6]. The carboxylate form and the lactone form of the molecule co-exist in equilibrium in aqueous solution and are $\mathrm{pH}$-dependent. As shown by Equation (1), the molecule is present in lactone form when the solution is acidic. The physiological $\mathrm{pH}$ value of human plasma is 7.4. This slightly basic environment is not favorable in the lactone form of camptothecin, and even worse, human serum

${ }^{*}$ Corresponding author. albumin has the highest affinity to the carboxylate form of the molecule [7], which causes the active form of the drug to disappear very rapidly when circulating in body. A number of attempts at improving lactone stability of camptothecin derivatives have been made. Acylation of $20-\mathrm{OH}$ of the molecule has been proven to be a successful way of obtaining stable camptothecins. A number of different reactions are reported in literature for preparing camptothecin esters. Direct acylation of camptothecin with organic acid anhydride as the acylating agent and pyridine as the reaction-helper was employed for preparing alkyl and alkenyl camptothecin esters [8,9] (Equation (2)). This reaction usually gives high yields, but the availability of organic acid anhydrides restricts the scope of the reaction.
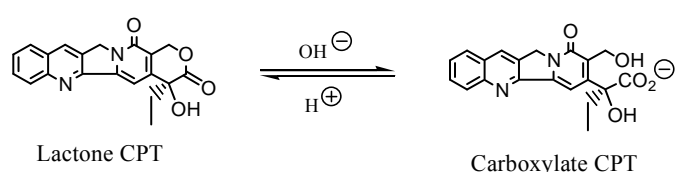

Carboxylate CPT
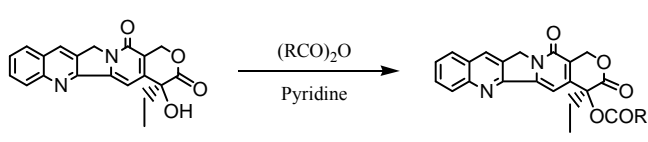

CPT

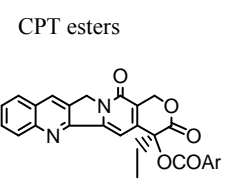

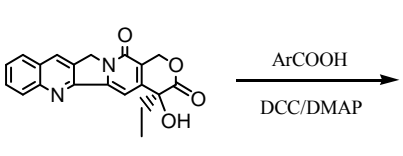

CPT

CPT esters 
Dicyclohexylcarbodiimide (DCC)/dimethylaminopyridine (DMAP) reagent system is frequently used for acylation reactions of carboxylic acids with alcohols [10-12] and thiols [10]. We previously used this method to prepare aromatic camptothecin esters [13] (Equation (3)). This procedure gives good reaction yields only when the carboxylic acids are very eletrophilic. When the acids are less electrophilic the reaction gives low yield or no expected product at all. For example, when using propionic acid to prepare camptothecin propionate with this procedure, we did not obtain the ester product, and the starting camptothecin was $100 \%$ recovered. We also used nonanoic chloride as an acylating agent to esterify camptothecin with pyridine as an HCl-trapping agent in methylene chloride [8]. The reaction occurred with low yield (6\%, Equation (4)).

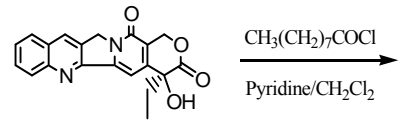

CPT

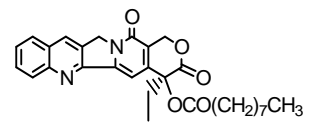

CPT nonanoate
Biological studies have demonstrated that camptothecin esters are potent as anti-cancer agents against human carcinomas grown in nude mice as xenografts, and that the toxicities of these esters in mice are low $[14,15]$. Thus, it is highly possible for camptothecin esters to become effective agents for the treatment of human cancers. Although there are many methods for preparing camptothecin esters, each procedure has certain restrictions as discussed above. Therefore, there is still a need to develop alternative procedure(s) for preparing camptothecin esters. The $\mathrm{H}_{2} \mathrm{SO}_{4}$-catalyzed preparation of camptothecin ester was previously proven to be more efficient than anhydride/pyridine when preparing crystalline camptothecin-20-O-propionate (CZ48) [16] and haloalkyl camptothecin esters [17]. In this report, we expanded this sulfuric acid-catalyzed reaction for preparing various different alkyl and alkenyl camptothecin ester compounds and found that this method was, indeed, more efficient than the previously reported preparations by giving higher reaction yields. The ester products generated by this preparation procedure had identical structural parameters as those reported and were active against human xenografts grown in nude mice. We now wish to report our experimental results.

\section{Methodology}

Chemistry: With excessive organic acid derivatives, such as acid chloride (or bromide) and acid anhydrides, as acylating agents and reaction media, camptothecins are allowed to react with them at room temperature or an elevated temperature under $\mathrm{N}_{2}$ atmosphere with a few drops of concentrate sulfuric acid as the catalyst. After subsequent work-up, camptothecin ester products are obtained in high yields.

General chemicals and equipment: Dry nitrogen was routinely used as the reaction atmosphere in all reactions. All glassware was baked at $70^{\circ} \mathrm{C} \pm 10^{\circ} \mathrm{C}$ for a minimum of $2 \mathrm{~h}$ before being used. Melting points were obtained with a MEL-TEMP melting point apparatus and were uncorrected. Camptothecin was purchased from The People's Republic of China and used as purchased. 9-nitrocamptothecin was prepared in our laboratory by using an established procedure [18]. The ${ }^{1} \mathrm{H}$ NMR spectrum of approximately $10 \%(\mathrm{w} / \mathrm{v})$ solution in $\mathrm{CDCl}_{3}$ was obtained at $399.93 \mathrm{MHZ}$, and ${ }^{13} \mathrm{C} \mathrm{NMR}$ at $100.57 \mathrm{MHz}$, with a Varion Unity PlusNMR spectrometer (Palo Alto, CA). Chemical shifts are reported in parts per million $(\delta$ scale), employing tetramethylsilane as an internal standard. Silica gel (70 - 230 mesh, Aldrich) for column chromatography was used for all product separations. Eastman chromagram (Silica gel with fluorescent indicator on polyethylene) sheets were employed in thinlayer chromatography (TLC) operations. Methylene chloride and THF solvents used as eluent for column chromatography were purchased from Fisher Scientific.

A typical procedure for preparation reaction: To a 200 $\mathrm{ml}$ round-bottomed flask equipped with a magnetic stirrer and a sand bath, were added $20 \mathrm{~g}$ camptothecin $(0.05747$ moles) and $100 \mathrm{ml}$ propionic anhydride (97\%, Aldrich Chemical Co., Milwaukee, WI). The mixture was heated by sand bath while stirring. A few drops ( 8 to 10) of concentrate sulfuric acid $(95 \%-98 \%$, A.C.S. reagent, Aldrich Chemical Co.) were added drop by drop when the sand bath temperature reached $80^{\circ} \mathrm{C}$. The mixture was then stirred at $110^{\circ} \mathrm{C} \pm 10^{\circ} \mathrm{C}$ for overnight $(\sim 14 \mathrm{hr})$. After cooling down to room temperature, the reaction mixture was poured onto $1000 \mathrm{ml}$ ice water portion by portion while stirring. After stirring for roughly $45 \mathrm{~min}$, the mixture was filtrated. The residue obtained from filtration was air-dry for $24 \mathrm{hr}$. The dried crude product was transferred to a $500 \mathrm{ml}$ round-bottomed flask equipped with a heating mantle. To this crude product was added $200 \mathrm{ml}$ absolute ethanol $(99.5 \%, 200$ proof, Aldrich Chemical Co.). The mixture was allowed to reflux for 2 $\mathrm{hr}$, and then cooled to room temperature. The pure product, camptothecin-20-O-propionate, was obtained as white crystals after crystallization from ethanol. Purity $99.8 \%$ (HPLC), mp $242^{\circ} \mathrm{C}$ (lit. [8] $250^{\circ} \mathrm{C}-252^{\circ} \mathrm{C}$ dec). TLC showed the identical $\mathrm{R}_{\mathrm{f}}$ values with the authentic camptothecin-20-propionate prepared in this laboratory previously. The ${ }^{1} \mathrm{H}$ and ${ }^{13} \mathrm{C}$ NMR also showed the same spectrum as the product reported previously [8].

With the same procedure and using the corresponding organic acid anhydride or chloride as acylating agents, all listed products in Table 1 were prepared in high yields.

Antitumor activity: A tumor xenograft growing in a nude mouse, approximately $1 \mathrm{~cm}^{3}$ in size, was surgically 
removed under sterile conditions, finely minced with iridectomy scissors, and suspended in cell culture medium at the ratio $1: 10, \mathrm{v} / \mathrm{v}$. One-tenth to one quarter of 1 $\mathrm{mL}$ of this suspension, containing about $50 \mathrm{mg}$ of wetweight tumor mince was subcutaneously inoculated on the upper half of the dorsal thorax of the mouse. Groups of six animals were used. Camptothecin ester product was finely suspended in cottonseed oil and then injected into the stomach cavity (IS) of the mouse through the anterior abdominal wall using a 26 gauge needle or administered intramuscularly (IM). The weekly schedule used for IS was five days on and two days off. The IM procedure was always performed on Monday and Thursday for each week. Treatment was initiated when the tumor had reached a volume of about $200 \mathrm{~mm}^{3}$, i.e., well-vascularized, measurable, and growing exponentially. Tumors growing in animals were checked daily and measured with a caliper two times per week. The effective doses were established when a positive response in mouse was reached.

\section{Results and Discussion}

Table 1 shows the comparison of the reaction yields of 11 camptothecin esters between the H2SO4-catalyzed acylation procedure and literature-reported procedures. The conventional anhydrides/pyridine procedure is frequently used in preparing ester compounds and usually gives high reaction yields when the corresponding anhydrides are available. As shown in Table 1, camptothecin-20-propionate, butyrate, valerate, and heptanoate are all obtained in high reaction yields. However, organic anhydrides are not always available. For example, we used nonanoyl chloride as an acylating agent rather than the corresponding anhydride when preparing camptothecin-20-nonanoate. In this situation, the reaction yield of the product was only $6 \%$. The DCC/DMAP procedure was actually not working for the preparations of the Table 1-listed CPT esters. The reactions we tried for preparation of camptothecin-20-O-propionate, camptothecin-20-O-butyrate, and 9-nitrocamptothecin-20-O-propionat did not generate the ester products, and the starting camptothecins were completely recovered. The $\mathrm{H}_{2} \mathrm{SO}_{4}$ catalyzed acylation of camptothecin derivatives with the corresponding acid anhydrides or chlorides gives high yields for every reaction as shown in Table 1. When nonanoyl chloride was employed as an acylating agent, the $\mathrm{H}_{2} \mathrm{SO}_{4}$-catalyzed reaction gave camptothecin-20nonanoate in a $92 \%$ yield, while the previously reported method in literature only gave $6 \%$.

Of 11 listed compounds in Table 1, camptothecin-20O-propionate, camptothecin-20-O-crotonate, and 9- nitrocamptothecin-20-O-propionate were very active against various human xenografts grown in nude mice. We previously reported the results of camptothecin-20-O-pro-
Table 1. Comparison of reaction yields of $\mathrm{H}_{2} \mathrm{SO}_{4}$-catalyzed esterfication of camptothecin with preothecin with previously reported procedure.

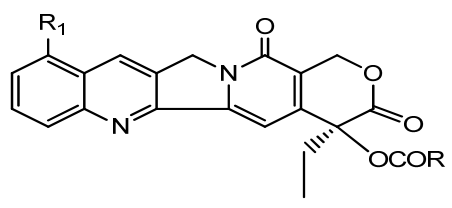

\begin{tabular}{cccc}
\hline \multirow{2}{*}{$\mathrm{R}$} & \multirow{2}{*}{$\mathrm{R}_{1}$} & \multicolumn{2}{c}{ Reaction yields (\%) } \\
\cline { 3 - 4 } & & Prevously reported & $\mathrm{H}_{2} \mathrm{SO}_{4}$-catalyzed \\
\hline $\mathrm{CH}_{3}$ & $\mathrm{H}$ & 58 & 96 \\
$\mathrm{C}_{2} \mathrm{H}_{5}$ & $\mathrm{H}$ & 94 & 99 \\
$\mathrm{C}_{3} \mathrm{H}_{7}$ & $\mathrm{H}$ & 92 & 98 \\
$\mathrm{C}_{4} \mathrm{H}_{9}$ & $\mathrm{H}$ & 90 & 99 \\
$\mathrm{C}_{6} \mathrm{H}_{13}$ & $\mathrm{H}$ & 98 & 99 \\
$\mathrm{C}_{8} \mathrm{H}_{17}$ & $\mathrm{H}$ & 6 & 92 \\
$\mathrm{CH}=\mathrm{CHCH}_{3}$ & $\mathrm{H}$ & 31 & 90 \\
$\mathrm{CH}_{3}$ & $\mathrm{NO}_{2}$ & 45 & 98 \\
$\mathrm{C}_{2} \mathrm{H}_{5}$ & $\mathrm{NO}_{2}$ & 73 & 99 \\
$\mathrm{C}_{3} \mathrm{H}_{7}$ & $\mathrm{NO}_{2}$ & 56 & 98 \\
$\mathrm{i}-\mathrm{C}_{3} \mathrm{H}_{7}$ & $\mathrm{NO}_{2}$ & 14 & 92 \\
\hline
\end{tabular}

pionate against 19 different human tumors [16]. Other two active compounds were also tested against various human tumors grown as xenografts in nude mice and found good anticancer activity. Particularly, 9-nitrocamptothecin-20-O-propinate showed spectacular results against the tumors tested. Figure 1 shows the results of this compound against 5 different human tumors and Figure 2 shows the toxicity of this compound at two effective doses in nude mice. The dose-dependence of this compound was observed at the low range. For example, the growth inhibition of this agent against MURbreast carcinoma was almost twice stronger at $2 \mathrm{mg} / \mathrm{kg}$ than $1 \mathrm{mg} / \mathrm{kg}$ (Figure 1(a)). This dependency disappeared when the dose was elevated to $10 \mathrm{mg} / \mathrm{kg}$ or higher. Figure 1(b) shows the results of the experiment with three different doses $(10 \mathrm{mg} / \mathrm{kg}, 20 \mathrm{mg} / \mathrm{kg}$, and $30 \mathrm{mg} / \mathrm{kg})$, and no significant differences in inhibitory effects between them were observed. This agent completely inhibits the growth of various types of human tumors in mice when the dose is $10 \mathrm{mg} / \mathrm{kg}$ or higher. Figures 1(c), (d) and (e) show that the growths of BRO-Melanoma, BRE-Stomach, and SPA-Lung in mice were completely inhibited. Two administration routes were used when treating SQU-Colon with $10 \mathrm{mg} / \mathrm{kg}$ of this compound. The result shown in Figure 1(f) clearly indicates that the inhibitory effect was identical when this agent was administered intrastomachly compared to when administered intramuscularly. The toxicity of this agent in mice at the effective dose was minimal. Figure 2 shows the body weight changes of mice during the period on treatment with this compound at $20 \mathrm{mg} / \mathrm{kg}$ and 30 $\mathrm{mg} / \mathrm{kg}$, respectively. At $20 \mathrm{mg} / \mathrm{kg}$ level, this agent was 


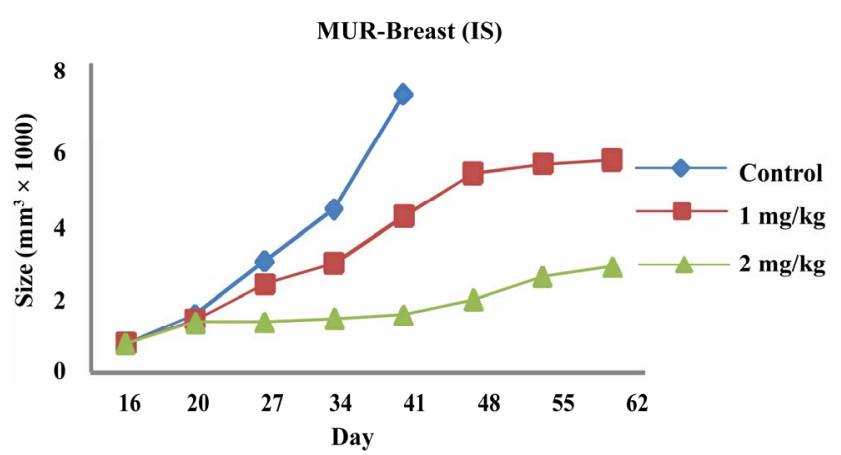

(a)

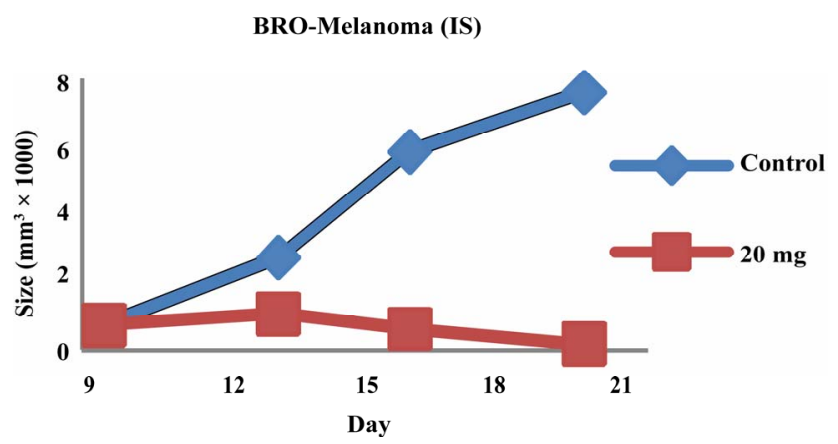

(c)

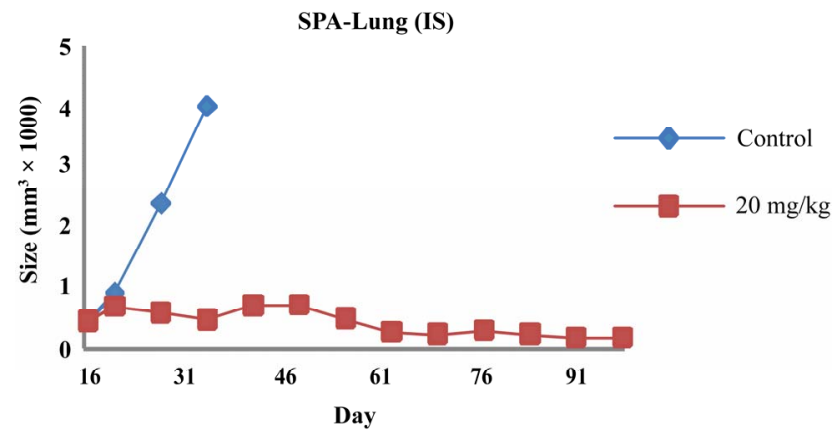

(e)

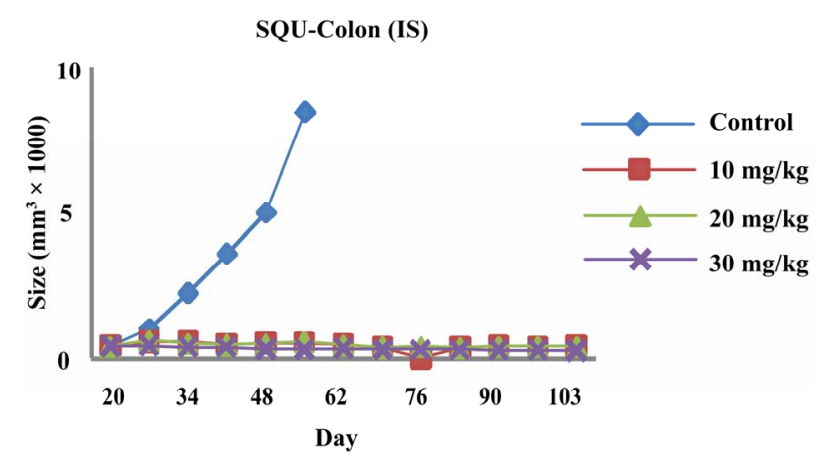

(b)

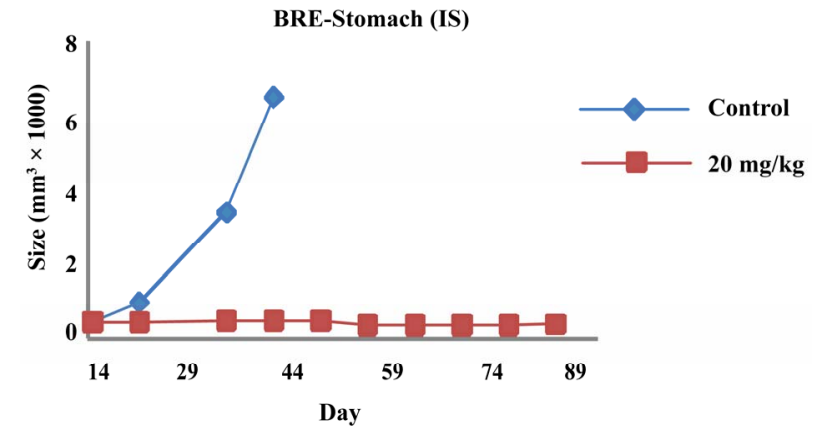

(d)

SQU-Colon (10 mg/kg)

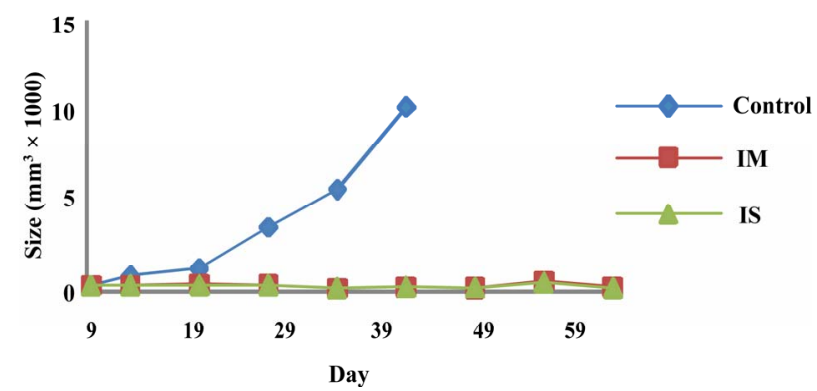

(f)

Figure 1. The anticancer activity of 9-nitrocamptothecin-20-O-propionate against various different types of human tumors grown as xenografts in nude mice. Each group had six same sizes of mice. All control groups of mice were sacrificed when tumors reached certain of sizes. $P \leq 0.05$.

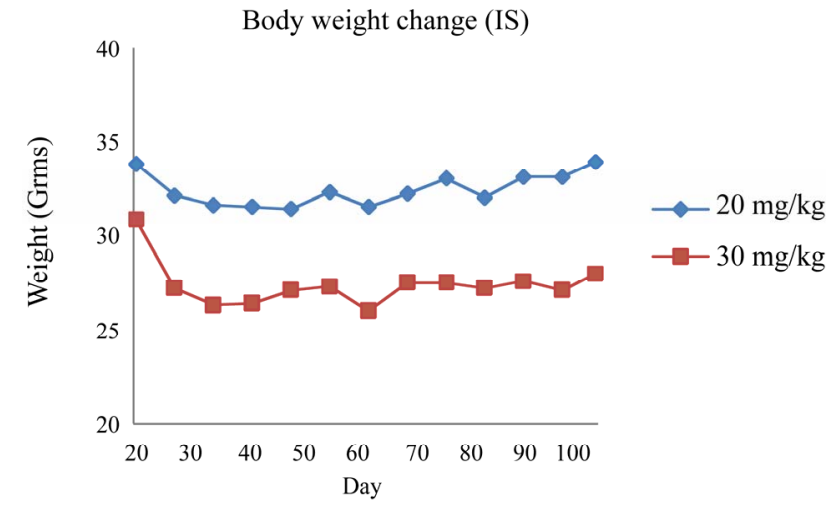

Figure 2. Toxicity of 9-nitrocamptothecin-20-O-propionate in mice at $20 \mathrm{mg} / \mathrm{kg}$ and $30 \mathrm{mg} / \mathrm{kg}$, respectively with a schedule of 5 days on and 2 days off. Group of 6 mice. $P \leq 0.05$. completely safe for animals. The end body weight was same as the initial weight. However, when dose reached $30 \mathrm{mg} / \mathrm{kg}$, sign of toxicity appeared because animals lost about $10 \%$ of their body weight. The effective dose of this agent was found to be smaller than $20 \mathrm{mg} / \mathrm{kg}$ against all types of the tumors tested in our laboratory. This compound has great potential to be developed for human treatment.

\section{Conclusion}

The $\mathrm{H}_{2} \mathrm{SO}_{4}$-catalyzed procedure gives us an efficient way for preparing camptothecin esters. The reaction gives higher yields compared to those procedures reported previously. The camptothecin ester derivatives prepared by this procedure showed great anticancer activity. Of active 
compounds, 9-nitrocamptothecin-20-O-propionate possesses great potential to be further developed for human treatment. This procedure would also be applicable to the acylation reactions of other alcohols or thiols.

\section{Acknowledgements}

The authors wish to thank Mr. Edward Ezell at the University of Texas Medical Branch for NMR data. Supporting funds from the CHRISTUS Stehlin Foundation for Cancer Research and the Friends of the Stehlin Foundation are greatly acknowledged.

\section{REFERENCES}

[1] M. Wall, M. Wani, C. Cook, K. Palmer, A. McPhail and G. Sim, "Plant Antitumor Agents. I. The Isolation and Structure of Camptothecin, a Novel Alkaloidal Leukemia and Tumor Inhibitor from Camptotheca acuminata," Journal of the American Chemical Society, Vol. 88, No. 16,1966, pp. 3888-3890. doi:10.1021/ja00968a057

[2] J. Gottlieb, A. Guarino, J. Call, V. Oliverio and J. Block, "Preliminary Pharmacologic and Clinical Evaluation of Camptothecin Sodium (NSC-100880)," Cancer Chemotherapy Reports: Part 1, Vol. 54, No. 6, 1970, pp. 461470.

[3] J. Gottlieb and J. Luce, "Treatment of Malignant Melanoma with Camptothecin (NSC-100880)," Cancer Chemotherapy Reports, Vol. 56, No. 1, 1972, pp. 103-105.

[4] F. Muggia, P. Creaven, H. Hansen, M. Cohen and O. Selawry, "Phase I Clinical Trial of Weekly and Daily Treatment with Camptothecin (NSC-100880): Correlation with Preclinical Studies," Cancer Chemotherapy Reports, Vol. 56, No. 4, 1972, pp. 515-521.

[5] C. Moertel, A. Schutt, R. Reitemeier and R. Hahn, "Phase II Study of Camptothecin (NSC-100880) in the Treatment of Advanced Gastrointestinal Cancer," Cancer Chemotherapy Reports, Vol. 56, No. 1, 1972, pp. 95-101.

[6] M. Wani, P. Ronman, L. Lindley and M. Wall, "Plant Antitumor Agents. 18. Synthesis and Biological Activity of Camptothecin Analogs," Journal of Medicinal Chemistry, Vol. 23, No. 5, 1980, pp. 554-560. doi:10.1021/jm00179a016

[7] T. Burke, "Chemistry of the Camptothecins in the Bloodstream: Drug Stabilization and Optimization of Activity in the Camptothecins-From Discovery to Patients," Annals of the New York Academy of Sciences, Vol. 903, 1993, pp. 29-31.

[8] Z. Cao, N. Harris, A. Kozielski, D. Vardeman, J. Stehlin and B. Giovanella, "Alkyl Esters of Camptothecin and 9-Nitrocamptothecin: Synthesis, in Vitro Pharmacokinet- ics, Toxicity, and Antitumor Activity," Journal of Medicinal Chemistry, Vol. 41, No. 1, 1998, pp. 31-37. doi:10.1021/jm9607562

[9] Z. Cao, J. Mendoza, A. DeJesus and B. Giovanella, "Synthesis and Antitumor Activity of Alkenyl Camptothecin Esters," Acta Pharmacologica Sinica, Vol. 26, No. 2, 2005, pp. 235-241. doi:10.1111/j.1745-7254.2005.00031.x

[10] B. Neises and W. Steglich, "Simple Method for the Esterification of Carboxylic Acids," Angewandte Chemie International Edition, Vol. 17, No. 7, 1978, pp. 522-524. doi:10.1002/anie.197805221

[11] A. Hassner and V. Alexanian, "Direct Room Temperature Esterification of Carboxylic Acids," Tetrahedron Letters, Vol. 19, No. 46, 1978, pp. 4475-4478 doi:10.1016/S0040-4039(01)95256-6

[12] F. Ziegler and G. Berger, "A Mild Method for the Esterification of Fatty Acids," Synthetic Communications, Vol. 9, No. 6, 1979, pp. 539-543. doi:10.1080/00397917908060958

[13] Z. Cao, J. Mendoza, A. DeJusus, D. Vardeman and B. Giovanella, "Synthesis and Antitumor Activity of Aromatic Camptothecin Esters," International Journal of Molecular Medicine, Vol. 21, No. 4, 2008, pp. 477-487.

[14] Z. Cao, P. Pantazis, J. Mendoza, J. Early, A. Kozielski, N. Harris and B. Giovanella, "Structure-Activity Relationship of Alkyl 9-Nitrocamptothecin Esters," Acta Pharmacologica Sinica, Vol. 24, No. 2, 2003, pp. 109-119.

[15] Z. Cao, P. Pantazis, J. Mendoza, J. Early, A. Kozielski, N. Harris, D. Vardeman, J. Liehr, J. Stehlin and B. Giovanella, "Structure-Activity Relationship of Alkyl Camptothecin Esters," Annals of the New York Academy of Sciences, Vol. 922, 2000, pp. 122-135. doi:10.1111/j.1749-6632.2000.tb07031.X

[16] Z. Cao, A. Kozielski, X. Liu, Y. Wang, D. Vardeman and B. Giovaniella, "Crystalline Camptothecin-20(S)-Opropionate Hydrate: A Novel Anticancer Agent with Strong Activity against 19 Human Tumor Xenograts," Cancer Research, Vol. 69, No. 11, 2009, pp. 4742-4749. doi:10.1158/0008-5472.CAN-08-4452

[17] Z. Cao, J. Mendoza, A. Kozielski, X. Liu, A. DeJesus, Y. Wang, C. Zhan, D. Vardeman and B. Giovanella, "Anticancer Activity of New Haloalkyl Camptothecin Esters against Human Cancer Cell Lines and Human Tumor Xenografts Grown in Nude Mice," Submission.

[18] Z. Cao, K. Armstrong, M. Shaw, E. Petry and N. Harris, "Nitration of Camptothecin with Various Inorganic Nitrate Salts in Concentrated Sulfuric Acid: A New Preparation of Anticancer Drug 9-Nitrocamptothecin," Synthesis, Vol. 1998, No. 12, 1998, pp. 1724-1730. doi: $10.1055 / \mathrm{s}-1998-2207$ 